\title{
CORPO E MARCA: TATUAGEM COMO FORMA DE SUBJETIVAÇÃO
}

\author{
Body and Mark: Tattoo as Form of Subjetivation \\ Cuerpo y Marca: Tatuaje como Forma de Subjetividad \\ Corps et Marque: Tatouaje comme Forme de Subjectivité
}

Artigo Original

\begin{abstract}
Resumo
O artigo tem a intenção de discutir as práticas corporais da pós contemporaneidade, iniciando com a ideia de corpo desenvolvida pela psicanálise. Tais práticas, analisadas a partir da ideia de constituição do eu freudiano e da cultura do consumo, representam a problemática fundamental deste ensaio. Para essa empreitada, tomamos como partida a psicanálise e nos fundamentamos, principalmente, nos conceitos de Freud e Lacan, para compreendermos a apropriação do corpo pelo sujeito e as dinâmicas identificatórias envolvidas nesse processo. A sociedade de consumo e a manipulação do sujeito pelo sistema capitalista transformam o corpo em objeto de troca e fetiche, tornando-se, ele mesmo, um sintoma da cultura. Nesse contexto, a tatuagem surge como um ato que reordena socialmente as relações do sujeito com seu corpo e como tentativa de bordejar as angústias que assolam o sujeito pós moderno. Iniciamos com um breve histórico sobre o corpo até chegarmos à contemporaneidade. Percorremos os conceitos de narcisismo e do estádio do espelho, passando pela divisão fundamental do sujeito e pela noção de gozo, balizados nas teorias de Freud e Lacan. A partir do conceito de mal estar, desenvolvido por Freud em 1930, nos propomos a discutir o corpo, à luz da cultura de consumo, como objeto de gozo e fetiche para, finalmente, analisarmos a body art, mais especificamente a tatuagem, como forma de subjetivação.
\end{abstract}

Palavras-chave: corpo; marca; tatuagem; gozo.

\section{Abstract}

The article has the intention to discuss body practices in contemporaneity, starting with the idea of body developed by psychoanalysis. Such practices, analysed from the idea of freudian ego and the culture of consumption, represent the fundamental matter of this essay. In order to achieve this, we took psychoanalysis as a starting point and fundamented this work, mainly, in the concepts of Freud and Lacan, to understand the apropriation of the body by the subject and the identificatory dynamics envolved in this process. In this context, the tattoo appears as an act that socially realigns the relationship between the subject and its body, and as an attempt to border the anguishes that ravage the post-modernity subject. We initiate with a brief history of the body until we arrive at contemporaneity. We went through the concepts of narcisism and the stage of the mirror, passing by the fundamental division of the subject and the notion of joy based on the theories of Freud and Lacan. From the concept of discontentment, developed by Freud in 1930, we propose ourselves to discuss the body under the light of the culture of consumption, as an object of joy and fetish to, finally, analyse body art, more especifically tattoos, as a form of subjectivation.

Keywords: body; mark; tattoo; Joy.

\section{Resumen}

El artículo tiene la intención de discutir las prácticas corporales en la contemporaneidad, iniciando con la idea de cuerpo desarrolhada por el psicanálisis. Tales practicas, analizadas a partir de la idea de ego de Freud y de la cultura del consumo, representan la problemática fundamental de este artículo. Para lograr este objetivo, tomamos el psicanálisis como el punto de partida y fundamentamos este trabajo, principalmente, en los conceptos de Freud

\section{Sybele Macedo ${ }^{(1)}$ \\ João Luiz Leitão Paravidini ${ }^{(2)}$ Caio César Souza Camargo Próchno ${ }^{(3)}$} 1) Psicóloga clínica no CAPS /
Prefeitura Municipal de Uberlândia
Mestranda em Psicologia Aplicada - Eixo
Intersubjetividade - Instituto de Psicologia -
UFU, Uberlândia, MG.

2) Psicanalista, Professor Associado Universidade federal de Uberlândia- MG. Doutor em Saúde Mental (UNICAMP).

3) Professor Associado- 4 do Instituto de Psicologia da UFU, Uberlândia, MG. Doutor em Psicologia Social pelo Instituto de Psicologia da USP, Pós-doutor em Psicologia e Filosofia pela Universidade de Leipzig(Alemanha).
Recebido em: 15/04/2012

Revisado em: 29/08/2014

Aceito em: 14/09/2014 
y Lacan, para entender la apropiación del cuerpo por el sujeto y las dinâmicas identificatorias involucradas en este processo. En este contexto, el tatuaje surge como nu acto que reordena socialmente las relaciones que del sujeto con su cuerpo, y como una tentativa de haver fronteira a la ansiedades de lo sujeto posmoderno. Iniciamos con una breve historia del cuerpo hasta la contemporaneidad. Viajando por los conceptos de narcisismo $y$ del estadio del espejo, a través de la división fundamental del sujeto y la noción de goce, basados en las teorias de Freud y Lacan. Desde el concepto de mallestar, desarrolhado por Freud en 1930, nos proponemos analizar el cuerpo, a luz de la cultura de consumo, como objeto de goce e fetiche y, por último, analizar el arte corporal, más especificamente los tatuajes, como formas de subjetividad.

Palabras clave: cuerpo; marca; tatuaje; goce.

\section{Résumé}

Cet article vise à discuter les pratiques corporelles de la contemporanéité, à commencer par l'idée du corps developpée par la psychanalyse. Les pratiques corporelles contemporaines, analysées à partir de l'idée de la constitution de l'ego freudien et la culture de consumèrisme, représentent le problème fondamental de cet essai. Pour cette tâche, nous prenons de départ la psychanalyse et nous avons considéré principalement les concepts de Freud et de Lacan, pour comprendre l'appropriation du sujet et de la dynamique identificatoires du corps impliqués dans cet processus. La société de consommation et le traitement du sujet par le système capitaliste transforment le corps en un objet de fétichisme et d'échange, devenant, lui-même, un symptôme de la culture. Dans ce contexte, le tatouage apparaît comme un acte social qui réorganise la relation du sujet avec son corps, et comme une tentative de virer les troubles dont souffre le sujet postmoderne. Nous commencerons par un bref historique du corps jusqu'à ce que nous atteignons la contemporainéité Transverson les concepts de narcissisme et du stade du miroir, à travers la division fondamentale du sujet et la notion de joissance, basé dans les théories de Freud et de Lacan. De la notion de malaise, développé par Freud en 1930, nous proposons de discuter le corps, à la lumière de la culture de consommation comme objet fétiche pour le jouissance et, enfin, d'analyser l'art corporel, tatouage, plus précisément, comme forme de subjectivité.

Mots-clés: corps; marque; tatouage; joissance.

Se o homem (...) não tivesse o que se chama um corpo, não estaria profundamente capturado pela imagem desse corpo (Lacan, 2007, p.3)

A concepção contemporânea de corpo é efeito de uma mudança na atmosfera sociocultural, manifestada de diversas formas e cada vez mais perceptível na clínica psicanalítica. O corpo vem despertando, progressivamente, o interesse dos sujeitos e da mídia e ganha destaque na lógica que rege a cultura do consumo. Le Breton (2011a), antropólogo francês, destaca a corporeidade humana "como fenômeno social e cultural, motivo simbólico, objeto de representações e imaginários" (p.7), destacando-a como um novo campo da sociologia. $O$ autor percebe o corpo como um importante elemento da expressão humana, primordial para compreender a relação do homem com o mundo e considera que, "antes de qualquer coisa, a existência é corporal" (p. 7) e o corpo, segundo o autor, "é o vetor semântico pelo qual a evidência da relação com o mundo é construída" (p.7). Sem o corpo o homem não existiria, não seria capaz de reduzir continuamente o mundo ao seu corpo, a partir do simbólico que ele encarna (Le Breton, 2011b). Assim, na falta de realizar-se em sua própria existência, os sujeitos procuram realizar-se por meio de seus corpos.

O corpo toma a frente da cena no palco da pós modernidade, constituindo-se como fonte de sofrimento, de frustração, de insatisfação e de impedimento à potência fálico-narcísica. O corpo, veículo da satisfação pulsional, com o advento do cristianismo, tornou-se também meio de expressão da dor e do sofrimento, que, de acordo com Fernandes (2003), parece encontrar dificuldades para se manifestar em termos psíquicos.

Lazzarini e Viana (2006) assinalam que o corpo, para a psicanálise, não é uma experiência primária. O sujeito só tem acesso ao seu corpo submetendo-se a uma série de ações que são mediatizadas sempre no simbólico. As tatuagens podem ser vistas como uma tentativa de acessar este corpo, que também é lugar de realização do desejo inconsciente.

$\mathrm{O}$ uso das tatuagens nas sociedades ocidentais já serviu como forma de marcar determinados grupos marginalizados, tais como marinheiros, prostitutas e presidiários; no entanto, hoje observamos uma difusão desta prática que vem ocupar seu lugar nos mais distintos grupos. $\mathrm{O}$ ato de inscrição simbólica no corpo aparece como uma tentativa do sujeito de ser singularizado para, assim, ser mostrado ao outro. A utilização de práticas de intervenção corporal (como a body art), apontam para uma busca pela singularidade em uma época em que as diferenças tendem a ser aniquiladas e representam uma estratégia última de experimentar a existência através do reconhecimento pelo olhar do outro.

\section{O Corpo: Breve Histórico}

O corpo é um objeto que assume caráter subjetivo na pós modernidade, especialmente se o considerarmos a partir da cultura do consumo. O corpo ocidental encontra-se em constante metamorfose. Não se trata mais de aceitá-lo, mas de modificá-lo e reconstruí-lo, sustentando-se um hedonismo característico da contemporaneidade (Baudrillard, 2008).

Na pós modernidade os sujeitos têm sido incentivados a manter formas corporais que, embora pareçam possíveis, na verdade nunca são completamente atingíveis e a condição 
real do corpo é constantemente negada e omitida. O corpo tornou-se também um modo e um lugar de inscrição, não somente subjetiva, mas também histórico social. A pele facilita essas inscrições por ser superfície lisa na qual se pode escrever uma história e também o meio de se exprimir as relações com a própria história (Maroun \& Vieira, 2008).

Nas culturas do mundo primitivo o corpo era frequentemente concebido como parte do universo, como aquilo que une e permeia as relações do sujeito com o mundo. Desde os primórdios do cristianismo, a relação com o corpo no Ocidente foi regida pela somatofobia. O corpo, inicialmente sacralizado e identificado com o corpo religioso cristão, era tido como obra prima de Deus e era marcado pela aversão e ódio e também pela hostilização ao prazer. Houve grande influência do Cristianismo na apreensão do corpo e dos males que o afetam. O corporal era considerado impuro e a dualidade bem/mal se transpunha no corpo/alma (Ceccarelli, 2011). Na Idade Média, com o aumento da influência da Igreja Católica, as relações estabelecidas com o corpo indicavam que a tendência era concebê-lo como algo pecaminoso, desvalorizado e profano. "O bem da alma estava acima dos desejos e prazeres da carne" (Maroun \& Vieira, 2008, p.174).

O corpo é reabilitado na Renascença e surge então o corpo moderno, "singularizado em sua anatomia e com atributos independentes de fatores imaginários e de forças ocultas" (Ceccarelli, 2011). O corpo é apropriado pelos artistas e passa a ser manipulado, sentido, auscultado e dissecado, surgindo aí os primeiros esboços de uma construção imaginária. Concebido como algo belo, começa a ter destaque, especialmente nas artes, em obras de artistas como Michelangelo, Da Vinci e Boticelli.

A partir do século XIX, o corpo passa a ser acessível à cultura de massa. A fotografia e as artes possibilitam sua contemplação estética, antes restrita à pintura e à escultura. Assim, seguindo a lógica industrial, a reprodução das imagens corporais pode atingir um número elevado de indivíduos, democratizando o que antes era privilégio da parcela dominante da sociedade (Maroun \& Vieira, 2008).

A apropriação do corpo é algo recente na cultura ocidental e a psicanálise possibilitou ao sujeito uma maior compreensão de sua dinâmica pulsional, permitindo assim o conhecimento de sua dinâmica identificatória (Fernandes, 2011). O interesse da psicanálise pelo corpo teve início com os estudos de Freud sobre a histeria, obra na qual o autor contrapõe o corpo biológico ao corpo marcado pelo desejo inconsciente e atravessado pela linguagem. $\mathrm{O}$ inconsciente se revela através das manifestações conversivas e de sintomas psicossomáticos; ou seja, é a linguagem inscrita no corpo que torna possível a descoberta do inconsciente.

\section{O Sujeito: Corpo e Carne}

O corpo é, ao mesmo tempo, origem e sede dos conflitos pulsionais que o sujeito experimenta psiquicamente como sensações. A anatomia passa a ser entendida como uma anatomia construída a partir dos investimentos libidinais, mediatizada pelo fantasma (Ceccarelli, 2011). Freud considera que o eu está ligado a uma imagem do corpo próprio; ele é, antes de tudo, um eu corporal; a projeção mental de uma superfície (Freud, 1923/2006e).

Entendemos que a unificação do corpo como imagem precisa ser estruturada a partir do enlace com o desejo do outro, uma vez que o infans não se reconhece como portador de um corpo, senão nesta amarração imagética alteritária. Embora o eu não esteja articulado desde o princípio, as pulsões auto eróticas já ali se encontram. O auto erotismo tem como característica a vivência de um corpo fragmentado e a ação de pulsões parciais que surgem e são satisfeitas na mesma zona erógena; cabe aqui destacar a pulsão escópica que se realiza no olhar e que se dá no ver e no ser visto. É preciso que uma nova ação psíquica, que Lacan chamará de "estádio do espelho", seja adicionada ao auto erotismo para que o narcisismo se constitua.

A teoria do narcisismo, introduzida por Freud (1914/2006c), implica que um corpo só se torna sexualizado porque se oferece ao olhar do outro; para Lacan (1998), a imagem do eu é constituída a partir da relação com esse outro/Outro, ou seja, da relação com o outro imaginário e com Outro, lugar do simbólico, definido também como o "lugar onde se constitui o sujeito" (Roudinesco \& Plon, 1998, p. 559). Nesse momento, definido como objeto de amor, o eu passa a ser objeto das pulsões, de modo que o narciso é tornar-se a si mesmo objeto de amor. Nessa nova concepção de Freud (1914/2006c), o eu tem uma unidade ilusória em relação à fragmentação do auto erotismo e das pulsões parciais, passando a ser considerado um grande reservatório de libido, de onde ela (a libido) é enviada para os objeto, recebendo aquele, também, parte da libido que destes reflui.

Em O Estádio do Espelho como formador da função do eu (je) ${ }^{1}$, (Lacan, 1998), Lacan postulou a constituição do Eu ligada à imagem do corpo próprio. Ao ver sua imagem no espelho, a criança, que inicialmente não reconhecia a imagem refletida como uma imagem de si, reconhece o seu próprio corpo e experimenta uma visão global que a leva ao júbilo. É necessário, porém, que um terceiro signifique essa imagem no campo da linguagem. Esse corpo 1 Para Lacan o eu freudiano se distingue entre o je (sujeito do inconsciente) e o moi (o eu imaginário). Nessa divisão, o moi, traduzido simplesmente como eu, é aquele que se formou a partir do outro; enquanto o je, representado por "eu" nas traduções para o Português, é o sujeito do inconsciente, aquele que aparece no discurso do analisando e que revela a verdade inconsciente e desejante (Lacan, 1998; Françóia, 2007). 
imaginário apresenta-se como uma unidade com a qual o sujeito identifica-se, mas, para que o recém-nascido habite seu corpo é necessário que aqueles que o introduzem no simbólico também se reconheçam possuidores de um corpo erógeno, com as possibilidades e limitações que lhe são características (Ceccarelli, 2011).

Para Lacan (1998), o narcisismo é um período de gozo com a própria imagem unificada. A imagem do corpo é marcada pelo olhar do Outro, olhar que é considerado como aquilo que insere e marca o sujeito e que, segundo Lacan (2008) é sempre diferente daquilo que imaginamos no campo do Outro. Enquanto antes se vivenciava como um corpo desmembrado, por meio da experiência imaginarizante, a criança antecipa o domínio do seu corpo, achando-se, por isso mesmo, cativada, fascinada pela imagem no espelho, e nela se rejubila. Ao se tomar pela imagem, o infans identifica-se com ela, mas essa imagem, de fato, não é ele. Ao mesmo tempo em que ela lhe dá a ilusão de unidade do eu, dele se separa como algo externo, outro. Trata-se de "uma armadura que reforça a impressão de uma rigidez alienada no outro" (Castilho, 2009), na qual a criança experimenta sua imagem condensada no olhar daquele que a olha. $\mathrm{O}$ eu se forma, portanto, inevitavelmente, por meio da imagem do outro: é o outro que possui sua imagem, com a qual se revalidará. Além disso, a forma ideal, vislumbrada na sua globalidade em um instante fugidio, irredutível e intermitentemente ansiado daí por diante, o ser humano jamais conseguirá reencontrar. É esse o eu ideal com o qual a criança identifica-se; porém, entre esse eu ideal e o eu real sempre faltará algo, dando lugar, então ao ideal do eu, no qual o sujeito deposita aquilo que falta para que o eu real torne-se o eu ideal. O sujeito freudiano é dividido na medida em que o eu real está muito aquém do eu ideal. Aquilo no qual o sujeito se sustenta, não é, necessariamente, o eu real. Essa divisão fundamental da condição inconsciente do sujeito proporciona um resto que se faz sempre presente na forma de um mal estar e provoca o desencontro do sujeito e sua impossibilidade de totalização.

$O$ ideal do eu representa um ponto essencial da economia libidinal. Todas as vezes que o sujeito se vê em situações nas quais seu narcisismo é ferido, ele busca recuperá-lo na forma do eu ideal. O ideal do eu, por sua vez, representa uma idealização, uma projeção imaginária do ideal sobre o objeto. Segundo Kyrillos (2008), o ideal do eu tem uma "função tipificadora no desejo do sujeito (...) e é fundamental no enlaçamento do sujeito ao Outro" (p. 8).

Enquanto antes se vivenciava como um corpo desmembrado, por meio da experiência imaginarizante, a criança antecipa o domínio do seu corpo, achando-se, por isso mesmo, cativada, fascinada pela imagem no espelho, e nela se rejubila. Ao se tomar pela imagem, o infans identifica-se com ela, mas essa imagem, de fato, não é ele.
Ao mesmo tempo em que ela lhe dá a ilusão de unidade do eu, dele se separa como algo externo, outro. Trata-se de "uma armadura que reforça a impressão de uma rigidez alienada no outro" (Castilho, 2009), na qual a criança experimenta sua imagem condensada no olhar daquele que a olha. $\mathrm{O}$ eu se forma, portanto, inevitavelmente, por meio da imagem do outro: é o outro que possui sua imagem, com a qual se revalidará. Além disso, a forma ideal, vislumbrada na sua globalidade num instante fugidio, irredutível e intermitentemente ansiado daí por diante, o ser humano jamais conseguirá reencontrar. É esse o eu ideal com o qual a criança identifica-se; porém, entre esse eu ideal e o eu real sempre faltará algo, dando lugar, então, ao ideal do eu, no qual o sujeito deposita aquilo que falta para que o eu real torne-se o eu ideal. O sujeito da psicanálise é dividido. Assim, aquilo no qual o sujeito se sustenta, não é, necessariamente, o eu real. Essa divisão fundamental da condição inconsciente do sujeito proporciona um resto que se faz sempre presente na forma de um mal estar, e provoca o desencontro do sujeito e sua impossibilidade de totalização.

O ideal do eu representa um ponto essencial da economia libidinal. Quando o sujeito se vê em situações nas quais seu narcisismo é ferido, ele busca recuperá-lo na forma do eu ideal. O ideal do eu, por sua vez, representa uma idealização, uma projeção imaginária do ideal sobre o objeto. Segundo Kyrillos (2008), o ideal do eu tem uma "função tipificadora no desejo do sujeito (...) e é fundamental no enlaçamento do sujeito ao Outro" (p. 8). Em Psicologia das Massas e Análise do Ego (Freud, 1921/2006d), Freud analisa 3 modalidades de identificação. A primeira delas é a chamada identificação primária e corresponde à forma originária do laço afetivo com o objeto. Trata-se de uma identificação pré-edipiana e canibalesca, colocando em pauta a noção de incorporação que foi, mais tarde, explorada pelos teóricos das relações objetais. A segunda é a identificação como substituto regressivo da escolha de objeto abandonada, e a terceira caracteriza-se por um elemento comum tomado do outro. A primeira delas, anterior ao complexo de Édipo, destaca o pai como ideal do eu e é acompanhada pelo investimento sexual direcionado à mãe. O ideal do eu corresponde, assim, aos ideais a serem alcançados na vida adulta. $\mathrm{O}$ estádio do espelho é a matriz simbólica da constituição subjetiva, pois é a partir dele que a criança consegue construir a imagem de seu corpo de maneira organizada. O corpo, antes vivido pela criança como um corpo despedaçado, passa a ser representado por uma forma unificada, revelando aquilo que ficou capturado no espelho. A imagem narcísica passa a ser uma das condições do aparecimento do desejo, pois a imagem do corpo representa o primeiro ponto de engate dos significantes do desejo do outro. Simultaneamente, a pulsão não cabe na imagem, resta sempre uma parcela sexual 
que fura a imagem. É por isso que o estádio do espelho estrutura, simultaneamente, não apenas o real, mas também o simbólico e o imaginário.

De acordo com Cukiert e Priszkulnik (2002), Lacan articula o corpo aos três registros, o imaginário, o simbólico e o real. O corpo imaginário é aquele que se apresenta como forma imaginária à qual o sujeito se identifica a partir do estádio do espelho pela mediação de um terceiro. O corpo simbólico é o corpo habitado pela linguagem que o desloca do gozo. Para os autores Lacan, o sujeito se produz na relação diferencial entre um significante para outro significante, ou seja, é na cadeia significante que o desejo se inscreve e o desejo é aquilo que nos protege contra o gozo. Assim, é o discurso do Outro que irá moldar nossas fantasias e desejos. O corpo real é o corpo pulsional, é o que resta após a incorporação da linguagem. Cukiert e Priszkulnik (2002) explicam que do ponto de vista do imaginário temos o corpo como imagem; do ponto de vista do simbólico, o corpo marcado pelo significante; e do ponto de vista do real, o corpo como sinônimo de gozo. Do ponto de vista do imaginário, levam-se em conta os primeiros momentos da teoria lacaniana e a forma como a imagem do corpo próprio, a partir do outro, marca a constituição subjetiva e a imagem assumida pelo sujeito. A abordagem do simbólico, trabalha a partir da relação estabelecida entre fala-linguagem-corpo e diz respeito ao corpo marcado pelo simbólico, no qual as diversas partes podem servir de significantes, indo além de sua função no corpo orgânico. Do ponto de vista do real, o corpo seria sinônimo de gozo, definido não como organismo, mas como pura energia psíquica. Assim, assinala Ribeiro (2010),

(...) o estatuto do corpo toma-o pelo registro do real como esta 'libra de carne', inerte; pelo registro do imaginário, o tem como lugar de inscrição, pulsional e exógeno, e pelo registro do simbólico assegura o lugar do código e da mensagem, da comunicação e da evocação, bordejando como pode a falta fundadora, aquela que nos torna humanos. (p. 64)

Para Lacan (2007), a ideia que alguém tem de si como um corpo é sustentada, na maioria das vezes, pela relação que um indivíduo estabelece com a imagem do próprio corpo. Isso vem de um prolongamento das investigações de Freud (1893/2006a) sobre as manifestações corporais das histéricas, postulando a existência de um corpo libidinal com regras de funcionamento distintas daquelas que compõem o corpo anatômico ou fisiológico que monopoliza a atenção da medicina.

Mandil (2008) acrescenta que o corpo é algo do qual nos apossamos em um determinado momento de nossa subjetivação e que, sempre haverá uma defasagem entre o ser e o corpo. Lacan (ano) ensina que, para que seja possível ter uma concepção de si, é necessário que ela se sustente sobre algo que não seja apenas "a desordem de pequenos (a)". A passagem do corpo fragmentado para a imagem de um corpo unificado é, portanto, um ponto de apoio sobre o qual o eu se constitui enquanto ideia de si mesmo como corpo (Mandil, 2008). Em termos libidinais, esta é a passagem do auto erotismo ao narcisismo.

Dunker e Kyrillos (2006) assinalam que em Freud (ano) o corpo possui um duplo estatuto, sendo por um lado, uma forma de objetificação do eu, no qual ele enuncia radicalmente sua alienação: eu sou isso; e por outro, fonte suposta das pulsões, "mola energética do sujeito" (p. 111). Segundo estes autores, o dilema "tenho um corpo", "sou um corpo", ou "estou envolvido ou possuído por um corpo" não escapa à alienação primaria que é fazer do que é sujeito um objeto, uma forma-imagem na qual o sujeito pode se reconhecer.

Lacan, através do mito da entrada no campo simbólico, sugere que a carne é uma espécie de resíduo necessário para a constituição de um corpo. Ela é o corpo antes que haja o corpo propriamente dito, ou seja, como função de identificação imaginária do sujeito. $\mathrm{O}$ corpo é efeito da carne, é a imagem que se articula no simbólico, sendo o real a carne. Somos então essa relação entre corpo e carne. Dizer que corpo e carne são coisas diversas é fundamental para a teoria lacaniana da corporeidade, e esta posição é dualista, isto é, o corpo é dual: é carne encorporada (Cukiert \& Priszkulnik, 2002; Dunker \& Kyrillos, 2006).

Este corpo dual é articulado entre simbólico e imaginário, tendo a matéria própria de uma narrativa e a estrutura, ou forma, própria de um discurso. Este corpo é inacessível ao sujeito em sua totalidade direta e indiretamente, e só é possível a ele reconhecê-lo, quando o reconhece, pelo olhar do outro. No entanto, esse outro não é um espelho neutro, mas, sim, um espelho "ideológico" (Dunker, 2006). Ele não mostra apenas a imagem do sujeito como um corpo, mas também o que ele espera, o que ele deseja ou exige dessa imagem. Esse espelho "ideológico" devolve ao sujeito aquilo que ele é, aquilo que não é, e aquilo que deveria ser (Dunker, 2006).

Isso produz uma insatisfação constitutiva, um estado de discordância com o "corpo próprio" ou ainda um "desconhecimento" de si neste corpo que se poderia prolongar para a identidade. $\mathrm{O}$ autor supra citado afirma com isso que a identidade é sempre virtual e também que ela contém uma patologia insuperável: o desconhecimento que ela produz ao afirmar-se. 


\section{Corpo: Mal Estar e Cultura do Consumo}

Freud, em "O Mal-estar na Civilização" (1930/2006e), chamou de mal estar o desconforto produzido pelas renúncias pulsionais que o indivíduo é levado a realizar em prol do sistema de interdições que constitui a civilização, isto é, as normas e valores sociais impostos e internamente absorvidos pelo supereu, este uma extensão da autoridade paterna. A renúncia ao incesto, à perversidade polimorfa e à promiscuidade, em benefício, respectivamente, da sexualidade exogâmica, da genitalidade e da monogamia têm suas consequências. Enquanto as pulsões sexuais são parcialmente sublimadas e transformadas em ideais coletivos, as agressivas são recalcadas e transferidas para o supereu que as dirige contra o próprio indivíduo sob a forma de sentimento de culpa. Os sujeitos eram marcados pela finitude, pela mortalidade e, consequentemente, pela angústia.

Assim, portanto, o mal estar resulta em frustração, culpa e ressentimento contra a civilização, consistindo em obter uma satisfação da renúncia pulsional. A condição humana leva o sujeito a obter gozo pela renúncia do próprio gozo, surgindo daí o sintoma. Para Bauman (1998, p.10),

(...) os mal-estares da modernidade provinham de uma espécie de segurança que tolerava uma liberdade pequena demais na busca da felicidade individual. Os mal-estares da pós-modernidade provêm de uma espécie de liberdade de procura do prazer que tolera uma segurança individual pequena demais.

A psicanálise reconhece que a natureza pulsional do homem é indomável, indomesticável e ineducável. Todavia, Freud (1901/2006b) foi além disso e universalizou o sintoma propondo que ele possa aparecer nas mais diversas formações do espírito e que varie em função da época. Sendo uma consequência do tipo de recalque próprio a cada cultura, os sintomas também se modificam de acordo com a cultura, ou seja, há sintomas novos tantos quantos forem os novos modos de gozo.

A contemporaneidade é caracterizada pela hegemonia da ciência e da tecnologia, regulada pelo mercado voltado essencialmente para o lucro e que promete, ilusoriamente, a realização de qualquer tipo de desejo, buscando fisgar consumidores de todas as classes, visando simplesmente, como Lacan já comentou, o consumo pelo consumo. A cultura do consumo significa não apenas a compra de bens e mercadorias para a satisfação de necessidades, mas também o consumo de imagens e valores. A sociedade, atravessada pelo imaginário, que pretende criar produções sociais sem falhas, é regida pelo desejo de onipotência e caracterizada por sujeitos que querem tudo dominar e que desenvolvem mecanismos defensivos muito fortes para negar ou transgredir as situações que, de modo algum, devem tocar aspectos do vazio ou da morte (Carreteiro, 2005).

Para adequar-se à lógica do consumo, o indivíduo é submetido à manipulação de suas necessidades pelo sistema que as transforma, quase sempre, em falsas necessidades individuais. "A grande velocidade de produção cria o imperativo de um rápido escoamento dos produtos, fomenta um forte consumo por parte da população, dando a impressão de que, sem este, o sistema ruiria" (Maroun \& Vieira, 2008).

A psicanálise sustenta que a promessa de completude não passa de um engodo, de uma propaganda enganosa. Partindo-se do princípio de que as relações humanas são organizadas por intermédio da linguagem, o homem encontra-se dividido, incompleto, estruturalmente barrado e impedido de atingir sua satisfação em total plenitude. Outrossim, parece ainda restar sempre ao sujeito uma nostalgia que busca recuperar aquilo que nunca se teve nem nunca se terá, e que Lacan, a partir de 1960, chamou de objeto a (Roudinesco \& Plon, 1998).

O sistema capitalista, agregado ao discurso científico, alimenta nessa sensação nostálgica de completude seu modo de funcionamento e de produção, ou seja, por meio da rotatividade de produtos potencialmente descartáveis dá ao sujeito a ilusão de que há algo que poderá preencher totalmente seu vazio. Nisso configura-se a cultura do consumo.

Para Lacan (1992), o sentido da sociedade de consumo se dá quando o humano é qualificado por um mais-degozar qualquer, sendo assim, equiparado a um produto forjado pela indústria. O proprietário torna-se material humano produtor dessa sociedade e é impulsionado pelo mandamento de trabalhar mais para produzir mais. Como os produtos não possuem estatuto de completude, deve-se continuar a produção.

Lacan (1992) formula, a partir de 1968, quatro formas discursivas onde encontramos 4 elementos: agente, Outro, verdade e produto. Esses quatro lugares são ocupados pelos seguintes elementos: significante mestre (S1), Saber (S2), sujeito barrado (\$) e objeto (a). Para o autor, o discurso pode ser um ato, um comportamento ou qualquer outro produto da linguagem e se expressa como laços sociais: o laço de governar e ser governado, representado pelo discurso do mestre; o laço de estudar e ser estudado, representado pelo discurso do universitário; o laço de analisar e ser analisado, representado pelo discurso do analista; e o laço de se fazer desejar, representado pelo discurso da histérica. Os discursos podem dispensar palavras e "conservam sua força nas relações fundamentais que se utilizam necessariamente da linguagem para se estabelecer" (Jacob \& Cohen, 2010). 
Nos discursos, os elementos circulam, ocupando diferentes posições em cada um deles.

Interessa-nos, neste trabalho, um quinto discurso, posteriormente desenvolvido e chamado de discurso do capitalista, considerado por Lacan (1992) não propriamente como um discurso, mas como uma inversão do discurso do mestre. Para Lacan (1992), a contemporaneidade destitui o antigo mestre de seu lugar e a este ascende um novo mestre, representado pelo sujeito. Este discurso não faz laço social e nele não há espaço para a falta, empurrando o sujeito cada vez mais para o isolamento. Segundo Le Breton (2011b, p.9), "o corpo moderno implica o isolamento do sujeito em relação aos outros", o que o autor chama de uma estrutura social do tipo individualista. O sujeito, não tendo mais o Outro consistente no qual se apoiar, identifica-se com o resíduo, com o objeto decaído do real (Jacob \& Cohen, 2010).

Nesse contexto, circunscreve-se o sujeito contemporâneo que, na busca pelo corpo perfeito ou por um corpo no qual se reconheça, tende a inscrever-se ao nível do ideal do eu, buscando, inconscientemente, um objeto que venha tamponar a falta original. O corpo, na pós modernidade, encarna uma promessa implícita de inclusão social, diferenciação, status, prazer, poder e felicidade (Severiano, Rêgo, \& Montefusco, 2010) e encarna o sujeito com o qual a psicanálise opera na contemporaneidade aquele que busca respostas imediatas para seu sofrimento.

\section{Corpo: Objeto de Gozo (Troca) e o Gozo do Objeto (Uso)}

As sociedades globalizadas concentram suas produções no efêmero, no volátil e no precário, com suas indústrias funcionando cada vez mais, produzindo bens cada vez mais frívolos, que duram cada vez menos, apenas o tempo da sensação que provocam, para serem ininterruptamente substituídos por novas sensações, que refletem a busca pelo prazer, característica da pós modernidade, onde o que importa é o aqui e o agora (Baudrillard, 2008; Maroun \& Vieira, 2008; Severiano et al., 2010).

Tais sensações, inevitavelmente, dizem respeito ao corpo. Trata-se aí de um novo modo de gozo que encontra no corpo seu alvo. Em consequência da substituição da moral pelo consumo, o corpo se tornou, de acordo com Baudrillard (2008), um objeto, inclusive, o mais belo objeto de consumo. Segundo o autor:

Após uma era milenária de puritanismo, a "redescoberta" do corpo sob a forma de o culto higiênico, dietético e terapêutico com que se rodeia, a obsessão pela juventude, elegância, virilidade/feminilidade, cuidados, regimes, práticas sacrificiais que com ele se conectam, o Mito do prazer que o circunda - tudo que hoje testemunha que o corpo se tornou objeto de salvação. Substitui literalmente a alma, nesta função moral e ideológica. (Baudrillard, 2008, p.168)

O sujeito passa a ser induzido a uma dupla prática do seu próprio corpo. Deve tratá-lo como capital, mas também como fetiche. Deve investir no corpo no duplo sentido do termo, tanto economicamente, quanto em sua acepção psíquica. A ditadura da imagem é então a ditadura do corpo ou, mais precisamente, a ditadura do gozo, muitas vezes nocivo, com a imagem do corpo. As imagens corporais passam a ser mercadorias em potencial, apostando no culto ao corpo como forma de afirmar-se existencialmente (Pollo, 2011).

Santaella (2008) considera que muitos dos modos contemporâneos de gozo levam ao corpo ou a ele se relacionam:

(...) os flagelos da carne no piercing e na tatuagem, os distúrbios alimentares na bulimia, anorexia e compulsão alimentar, a obesidade, o horror ao envelhecimento, a remodelagem contínua do corpo no body building, nas orgias do silicone, nas metamorfoses resultantes das cirurgias plásticas e, pautado na exaltação desses emblemas narcísicos, o exibicionismo exacerbado do corpo nas mídias e o consequente "voyerismo" institucionalizado. (Santaella, 2008, pp. 8-9)

Para a autora, "o corpo, ele mesmo, se tornou um sintoma da cultura, isto é, o corpo criou uma ancoragem entre o gozo e os imperativos da vida em sociedade" (Santaella, 2008, p.9). Diferentemente dos sintomas que antes se davam no corpo como ocorria com as histéricas que despertaram o interesse de Freud no final do século XIX, os sintomas foram tomando outra direção até tornarem o corpo, ele mesmo, sintoma da cultura.

\section{Tatuagem: Marca, Traço e Imagem}

A partir da década de 60 , as relações do indivíduo com os outros e com o mundo ampliam-se consideravelmente por meio de movimentos como o feminismo, a revolução sexual, a expressão corporal e a emergência da body art (Beneti, 2012; Ceccarelli, 2011). O real do corpo, quando visível, passa a ser ignorado e transformado pelas cirurgias plásticas, tatuagens, piercings, exercícios físicos, remédios e anabolizantes, demonstrando o lugar ocupado pelo corpo na cultura do consumo.

Dentre as práticas corporais características da contemporaneidade, a tatuagem vem ganhando destaque. Ao longo da história a tatuagem ocupou diferentes lugares 
e é considerada uma das formas de modificação corporal mais difundidas no mundo. Existem provas arqueológicas que afirmam que tatuagens foram feitas no Egito entre 4000 e 2000 AC. Os habitantes da Polinésia, Filipinas, Indonésia e os Maori da Nova Zelândia tatuavam-se em rituais ligados às práticas religiosas. A tatuagem foi banida da Europa pela Igreja Católica na Idade Média, que a caracterizava como prática demoníaca (Beneti, 2012; Ceccarelli, 2011; Costa, 2003).

Considerada arte proibida, ritual artístico complexo e decoração pagã, independente do contexto, ela "revela-nos um traço essencial do ser humano, a saber, a necessidade de processar e significar suas vivências e experiências e de lhes dar alguma forma de expressão" (Beneti, 2012, pp.12). Tais manifestações representam, na pós modernidade, formas de subjetivação.

As marcas corporais, como as tatuagens (ou dermopigmentações), apresentam-se como formas de linguagem que apontam para a subjetividade. Essas marcas, voluntariamente impressas no corpo, são consideradas por Moreira, Teixeira e Nicolau (2010) como formas de linguagem implicadas com a busca de identidade e como expressão do sujeito. As marcas corporais vão proliferando como tentativas de fazer face ao desamparo do sujeito por nunca encontrar o olhar desejado, perdido na infância, como estratégia de mascarar a falta primordial e, simultaneamente, de tentar representá-la e lhe dar sentido. Diferentemente da pintura corporal, a tatuagem é um livro encarnado que o sujeito carrega consigo e que mostra a necessidade que ele tem de tornar sua história visível para poder assumi-la ou torná-la mais suportável. "A tatuagem mantém o tempo na eternidade da pele viva" (Andrieu, 2004, p.20).

$\mathrm{Na}$ superfície da pele, o sujeito inscreve um traço de outrora, uma lembrança, um marco, um nome um desejo, um afeto. São, segundo García (2006), vestígios que expõem o território da subjetividade pregada na carne. A mensagem que a tatuagem carrega, traduz em iconicidade a representação figural de uma memória que para sempre permanece ali aplicada. Essa representação é somente alterada pelo envelhecimento que faz com que as rugas do corpo reforcem o estatuto provisório da imagem tatuada.

Para Costa (2003), as tatuagens, piercings e escarificações são marcas que buscam fazer borda, e têm a ver com a erotização e sua necessidade de suporte no Outro. $\mathrm{Na}$ ausência da palavra, o sujeito encontra outras formas de se expressar e de afirmar sua existência para si mesmo e para os outros. É preciso, portanto, "escutar" tais práticas como relacionadas à constituição psíquica que parecem remeter aos processos de construção do eu. Beneti (2012) sugere que devemos abordar a tatuagem a partir do laço social. Para isso é necessário pensar uma clínica que considere o sujeito, o objeto olhar e a pulsão. Assim, além da função que a tatuagem cumpre, devemos também escutar "a posição de cada um com relação à sua tatuagem, ao seu próprio corpo e ao endereçamento ao olhar do Outro" (Beneti, 2012 p. 6).

As tatuagens, tomadas por Beneti (2012) a partir da segunda clínica lacaniana, não seriam capazes de recuperar as propriedades borromeanas do nó ou de apontar para uma estabilização definitiva, mas poderiam representar algo capaz de produzir um "apaziguamento momentâneo, permitindo ao sujeito avançar". Essas marcas definem fronteiras objetivas e subjetivas, pois além de demarcarem os limites concretos do corpo, possibilitam a filiação a grupos através das marcas corporais e poderiam ser consideradas como

(...) tentativas de bordejar as angústias inomináveis e impensáveis que habitam o ser, ou mesmo de negar essas angústias primordiais, pois o corpo todo tatuado pode deixar de ser corpo para ser tela, livro. Algo que me faça esquecer a condição de finito, pois o corpo é a maior lembrança deste estado. (Moreira et al., 2010, p.592)

É importante lembrar que cada sujeito lida com a questão da tatuagem de maneira única, seja como tentativa de bordejar as angústias ou como instrumento capaz de promover um apaziguamento momentâneo. Tatuagens, de acordo com Costa (2003), são emblemas da composição em que a carne, sendo humana, traz em suas fibras já inscrita a cultura. Dessa forma, se há uma natureza humana, ela se define por ser social, por existir em relação ao seu meio, aos seus semelhantes e ao Outro. Seria interessante, como sugere Beneti (2012), investigar se a tatuagem seria capaz de auxiliar o sujeito a recuperar uma imagem una de si em determinados momentos críticos como nas psicoses ou na histeria, em que o sujeito poderia fazer uso da tatuagem para recompor algo da imagem endereçada ao olhar do outro e também investigar sua capacidade de se apresentar como a dor que ampara a ausência de palavras e que abre furos na pele do sujeito na tentativa de tamponar os furos imaginários deixados em sua infância perdida.

\section{Considerações Finais}

O corpo assume caráter de objeto de consumo na pós modernidade e passa a ser manipulado e modificado para, cada vez mais, satisfazer a lógica do consumismo, tornandose um sintoma da cultura. Nesse contexto, observamos a tatuagem mais e mais difundida e não apenas restrita aos guetos, e procuramos analisá-la como prática que aponta para a subjetividade. Retomando os pensamentos de Freud e Lacan sobre a constituição do eu, encontramos o sujeito contemporâneo buscando tamponar uma falta que 
é constitutiva, na tentativa de adequar-se à sociedade do consumo. Essa tentativa passa, inevitavelmente, pelo corpo, que é transformado e tratado tanto como capital quanto como objeto de fetiche. As tatuagens (assim como outras formas de body art) aparecem como marcas que tentam fazer borda às angústias e como tentativa de apaziguamento momentâneo. É preciso escutar a posição de cada sujeito em relação a essas marcas, formas de linguagem que parecem remeter à constituição do eu. Afinal, "se o homem (...) não tivesse o que se chama um corpo, não estaria profundamente capturado pela imagem desse corpo" (Lacan, [1975] 2007, p.3).

\section{Referências}

Andrieu, B. (2004). A nova filosofia do corpo. Lisboa: Instituto Piaget.

Baudrillard, J. (2008). A sociedade de consumo. Lisboa: Edições 70, LDA.

Bauman, Z. (1998). O mal-estar da pós-modernidade. Rio de Janeiro: Jorge Zahar.

Beneti, A. (2012). Tatuagem e laço social. Opção Lacaniana nova série [online], 3 (7), 1-19. Recuperado de http://www.opcaolacaniana.com.br/pdf/numero_7/ Tatuagem_e_laco_social.pdf..

Carreteiro, T. C. (2005). Corpo e contemporaneidade. Psicologia em Revista, 11(17), 62-76.

Castilho, P. T. (2009). A palavra através do espelho. Revista Estilos da Clínica, 14(26), 174-191.

Ceccarelli, P. R. (2011). Uma breve história do corpo. In E. S. N. Lange, \& L. S. P C. Tardivo (Orgs.), Corpo, alteridade e sintoma: Diversidade e compreensão (pp. 15-34). São Paulo: Vetor.

Costa, A. (2003). Tatuagens e marcas corporais: Actualizações do sagrado. São Paulo: Casa do Psicólogo.

Cukiert, M., \& Priszkulnik, L. (2010). Considerações sobre o eu e o corpo em Lacan. Estudos de Psicologia, 7(1), 143-149.

Dunker, C. I. L., \& Kyrillos, F. N. (2006). Identidade e a degradação da carne. Revista Mal-estar e Subjetividade, 6(1), 111-124.

Dunker, C. L. (1997). Tatuagem e sedução. Revista Viver Psicologia, 26.

Fernandes, M. H. (2011). Corpo (4a ed., Coleção Clínica Psicanalítica). São Paulo: Casa do Psicólogo.
Françóia, C. R. (2007). O simbólico e a clínica psicanalítica: O início da teoria lacaniana. Revista AdVerbum, 2(1), 87-101.

Freud, S. (2006a) Estudos sobre a histeria. In J. Strachey (Org.), Edição Standard Brasileira das Obras Psicológicas Completas de Sigmund Freud (vol. 2). Rio de Janeiro: Imago. (Originalmente publicado em 1893/1895)

Freud. S. (2006b). Sobre a psicopatologia da vida cotidiana. In Edição Standard das Obras Psicológicas Completas de Sigmund Freud (vol. 6). Rio de Janeiro: Imago. (Originalmente publicado em 1901)

Freud, S. (2006c). Sobre o narcisismo: Uma introdução. In J. Strachey (Org.), Edição Standard Brasileira das Obras Psicológicas Completas de Sigmund Freud (vol. 14). Rio de Janeiro: Imago. (Originalmente publicado em 1914)

Freud, S. (2006d). Psicologia das massas e análise do ego. In J. Strachey (Org.), Edição Standard Brasileira das Obras Psicológicas Completas de Sigmund Freud (vol. 18). Rio de Janeiro: Imago. (Originalmente publicado em 1921)

Freud, S. (2006e). O ego e o id. In J. Strachey (Org.), Edição Standard Brasileira das Obras Psicológicas Completas de Sigmund Freud (vol. 19). Rio de Janeiro: Imago. (Originalmente publicado em 1923)

Freud, S. (2006f). O mal-estar na civilização. In J. Strachey (Org.), Edição Standard Brasileira das Obras Psicológicas Completas de Sigmund Freud (vol. 21). Rio de Janeiro: Imago. (Originalmente publicado em 1930)

García, W. (2006). Corpo e subjetividade: Estudos contemporâneos. São Paulo: Factash Editora.

Jacob, C. A., \& Cohen, R. H. P. (2010). O sujeito contemporâneo: Um recorte psicanalítico. Revista Mal-estar e Subjetividade, 10(2), 537-554.

Kyrillos, F. N. (2008) Psicanálise e corpo na contemporaneidade. III Congresso Internacional de Psicopatologia Fundamental, IX Congresso Brasileiro de Psicopatologia Fundamental. Niterói, RJ,

Lacan, J. (2007). Conferência de Genebra sobre o sintoma. Texto para estudo veiculado na IPB-lista, tradução de Rita Smolianinoff, Recife, 23.12.2007.

Lacan, J. (1998). O estádio do espelho como formador da função do eu. In J. Lacan, Escritos (pp. 96-103). Rio de Janeiro: Jorge Zahar.

Lacan, J. (2008). O Seminário, Livro 11: Os quatro 
conceitos fundamentais da psicanálise (1964). Rio de Janeiro, Jorge Zahar.

Lacan, J. (1992). O seminário, Livro 17: O avesso da psicanálise (1969-1970). Rio de Janeiro: Jorge Zahar.

Lacan, J. (2007). O seminário, Livro 23: O sinthoma (19751976). Rio de Janeiro: Jorge Zahar.

Lazzarini, E. R., \& Viana, T. C. (2006). O corpo em psicanálise. Psicologia: Teoria e pesquisa, 22(2), 241249.

Le Breton, D. (2011a). A sociologia do corpo ( $\left.5^{\mathrm{a}} \mathrm{ed}\right)$. Petrópolis, RJ: Vozes.

Le Breton, D. (2011b). Antropologia do corpo e modernidade. Petrópolis, RJ: Vozes.

Mandil, R. (2008). James Joyce e a "Idéia de si como corpo". In Anais do XI Congresso Internacional da ABRALIC, 13 a 17 de julho de 2008. São Paulo, USP. Recuperado de http://www.abralic.org.br/anais/ cong2008/AnaisOnline/simposios/pdf/005/RAM MANDIL.pdf

Maroun, K., \& Vieira, V. (2008). Corpo: Uma mercadoria na pós-modernidade. Psicologia em Revista, 14(2), 171-186.

Moreira, J. O., Teixeira, L. C., \& Nicolau, R. F. (2010). Inscrições corporais: Tatuagens, piercings e escarificações à luz da psicanálise. Revista Latinoamericana de Psicopatologia Fundamental, 13(4), 585-598.

Pollo, V. (2011). O psicanalista e a ditadura da imagem. Laboratório de Psicanálise da UFC [Artigo]. Recuperado de http://www.psicanalise.ufc.br/hot-site/ pdf/Mesas/51.pdf

Ribeiro, M. M. C. (2010). As marcas corporais: O corpo como depositário das fantasias inconscientes. Reverso, 32(60), 61-66.

Roudinesco, E., \& Plon, M. (1998). Dicionário de psicanálise. Rio de Janeiro: Jorge Zahar.

Santaella, L. (2008). O corpo como sintoma da cultura. Revista Comunicação, Mídia e Consumo, 1(2) [online]. Recuperado de http://revistacmc.espm.br/index.php/ revistacmc/article/viewFile/28/28

Severiano, M. F. V., Rêgo, M. O., \& Montefusco, E. V. R. (2010). O corpo idealizado de consumo: Paradoxos da hipermodernidade. Revista Mal-estar e Subjetividade, 10(1), 137-165.

\section{Endereço para correspondência:}

Sybele Macedo

Endereço: Avenida José Zacharias Junqueira, 190 - apto 802. Santa Maria Uberlândia - MG - CEP: 38408-044. Tel: (034) 30846149 / (034) 99378898

E-mail: sy.macedo@gmail.com/sy_macedo@hotmail.com

\section{Endereço para correspondência:}

João Luiz Leitão Paravidini

Endereço: Av. Uirapuru, 934. Cidade Jardim Uberlândia MG. CEP: 38412-166

E-mail: jlparavidini@gmail.com ; paravidini@ufu.br.

\section{Endereço para correspondência:}

Caio César Souza Camargo Próchno

Endereço: Rua Cruzeiro dos Peixotos - 59 - apto. 203.

Aparecida Uberlândia - MG - CEP: 38400-608

Tels.: (034)32182827 / (034)91337742

E-mail: c.prochno@uol.com.br/caioprochno@terra.com.br 